\title{
Pengembangan Budaya Sekolah Berprestasi: Penanaman Nilai dan Etos Berprestasi
}

\author{
Ageng Pratiwi ${ }^{*}{ }^{*}$, Erny Roesminingsih ${ }^{2}$ (iD \\ 1,2 Jurusan Manajemen Pendidikan, Universitas Negeri Surabaya, Surabaya \\ *Corresponding author: ageng.19012@mhs.unesa.ac.id, ernyroesminingsih@unesa.ac.id
}

\begin{abstract}
Abstrak
Masalah disiplin dalam mentaati aturan sekolah, prilaku moncontek pada saat melaksanakan tes, budaya belajar dan membaca yang rendah, serta budaya kompetesi antar siswa yang juga dirasakan masih rendah. Tujuan penelitian ini adalah untuk menganalisis bentuk budaya sekolah berprestasi, proses penanaman nilai dan etos berprestasi di SMA. Penelitian ini menggunakan pendekatan deskriptif kualitatif. Pengumpulan data menggunakan teknik observasi, wawancara dan dokumentasi. Penelitian ini menggunakan sumber data berupa data primer dan data sekunder. Teknik analisis data menggunakan analisis data kualitatif. Hasil penelitian menunjukkan bahwa penanaman nilai dan etos berprestasi pada peserta didik dilakukan melalui kegiatan orientasi sekolah, proses pembelajaran, evaluasi belajar, ekstrakurikuler, penghargaan prestasi, kecintaan terhadap almamater, keteladanan guru, kerjasama dengan orangtua peserta didik dan seragam patriot sebagai media penanaman budaya berprestasi. Implikasi penelitian ini diharapkan dapat memberikan dampak bagi peserta didik dalam meningkatkan nilai dan etos berprestasinya.
\end{abstract}

Kata kunci: Budaya sekolah, nilai etos berprestasi

\section{Abstract}

Discipline problems in obeying school rules, cheating behavior when carrying out tests, low learning and reading culture, and a culture of competition among students which is also felt to be still low. The purpose of this study was to analyze the form of school culture of achievement, the process of inculcating values and the ethos of achievement in high school. This research use desciptive qualitative approach. Collecting data using observation, interview and documentation techniques. This study uses data sources in the form of primary data and secondary data. The data analysis technique used qualitative data analysis. The results showed that the inculcation of achievement values and ethos in students was carried out through school orientation activities, learning processes, learning evaluations, extracurriculars, achievement awards, love for the alma mater, teacher examples, collaboration with parents of students and patriot uniforms as a medium for inculcating a culture of achievement. The implications of this research are expected to have an impact on students in increasing their achievement values and ethos.

Keywords: school culture, achievement ethos

\begin{tabular}{|c|c|c|}
\hline History: & & Publisher: Undiksha Press \\
\hline Received & : 15 Desember 2019 & Licensed: This work is licensed under \\
\hline Revised & : 20 Januari 2020 & a Creative Commons Attribution 4.0 License \\
\hline Accepted & : 14 April 2021 & (c) (i) (2) \\
\hline Published & : 25 Juli 2021 & $\underbrace{\mathrm{SA}}_{\mathrm{EY}}$ \\
\hline
\end{tabular}

\section{Pendahuluan}

Pendidikan di sekolah pada hakikatnya merupakan usaha untuk mentransmisikan nilai kebudayaan, yang bertujuan mempertahankan, mengembangkan, dan mentransformasikan kebudayaan yang dimiliki masyarakat (Prayogi et al., 2019; Rahman et al., 2019). Pengembangan nilai, kelakuan, rencana dan strategi sekolah secara terpola menghasilkan suatu budaya sekolah yang dianut bersama oleh pelaku-pelaku di dalamnya (Ramdan \& Fauziah, 2019). Pendidikan merupakan faktor penting dan menentukan dalam kehidupan berbudaya, berbangsa dan berenegara(Hendra Anggryawan, 2018). Kemajuan suatu bangsa sangat tergantung pada tingkat pendidikan yang diperoleh rakyatnaya. Rakyat memperoleh pendidikan melalui mekanisme system pendidikan nasional yang telah ditetapkan. Sistem 
pendidikan nasional Indonesia dilaksanakan untuk meningkatkan kehidupan bangsa yang bermutu baik dalam arti moral spiritual maupun mutu dalam arti intelektual-profesional.

Indoensia telah memiliki sistem pendidikan nasional yang tertuang dalam Undangundang Sisdiknas No. 20 tahun 2003. Namun sejumlah permasalahan pendidikan masih dijumpai. Salah satu masalah yang dihadapi dunia pendidikan pada saat ini adalah masalah disiplin dalam mentaati aturan sekolah, prilaku moncontek pada saat melaksanakan tes, budaya belajar dan membaca yang rendah, serta budaya kompetesi antar siswa yang juga dirasakan masih rendah (Eva, 2016; Kurniawan, 2021). Permasalahan-permasalah tersebut menuntut sekolah mengembangkan budaya sekolah, seperti: budaya disiplin, rasa tanggung jawab, kejujuran, keikhlasan, etos belajar, kebiasaan memecahkan masalah secara rasional dan sebagainya. Budaya yang dikembangkan di sekolah akan menumbuhkan disipilin, etos belajar siswa menjadi manusia yang penuh optimis, berani tampil, berperilaku kooperatif dan memupuk rasa tanggung jawab dan rasa kebersamaan siswa (Permana \& Ulfatin, 2018; Silkyanti, 2019).

Budaya lebih mengacu kepada pengertian tingkah laku atau pola perilaku, kebiasaan, atau nilai dalam sistem nilai. Budaya sekolah merupakan ciri khas, karakter atau watak, dan citra sekolah tersebut di masyarakat luas(Kurniawan, 2021; Silkyanti, 2019). Penerapan budaya sekolah yang tepat akan mempunyai pengaruh yang berarti dalam aktivitas belajar siswa, maupun dalam mempengaruhi guru untuk melakukan pekerjaan yang lebih efisien dan efektif untuk mencapai kinerja guru yang baik. Budaya sekolah akan mempengaruhi suasana kelas, baik kebebasan yang dinikmati peserta didik dalam mengembangkan pikiran dan prestasinya ataupun sebaliknya bisa menjadi pengekangan dan keterbatasan tehadap pengembangan peserta didik dan sekolah itu sendiri (Rachmawati et al., 2018). Penanaman nilai-nilai budaya sekolah dilaksanakan terutama saat pembelajaran di kelas dan akan berlanjut dalam pola kelakuan dan interaksi di luar kelas. Peserta didik pada saat pertama memasuki lingkungan sekolah akan mengalami proses sosialisasi dimana peserta didik memahami dan menjalankan budaya sekolah. Proses pembelajaran peserta didik dapat berjalan lancar karena ada budaya sekolah yang menentukan kelakuan dan tujuan yang diharapkan oleh guru, peserta didik dan para stakeholder. Nilai-nilai dan norma yang berlangsung di dalam sekolah juga harus memperhatikan budaya masyarakat terutama yang berlaku dalam keluarga peserta didik.

Budaya berprestasi merupakan bentuk budaya sekolah yang menjadi poin utama di setiap sekolah(Polapa, 2018; Pratama et al., 2019). Motivasi yang paling penting untuk pendidikan adalah motivasi berprestasi, seseorang cenderung berjuang untuk mencapai sukses atau memilih suatu kegiatan yang berorientasi untuk tujuan sukses atau gagal (Asiyah, 2019; Rozaini, 2017). Ada beberapa hal yang mempengaruhi motivasi berprestasi, yakni keluarga dan kebudayaan; konsep diri; jenis kelamin dan pengakuan prestasi. SMA Muhammadiyah 10 Surabaya merupakan sekolah berprestasi yang memiliki suatu karakter budaya sekolah yang berbeda dengan sekolah lainnya. Banyak prestasi yang telah diraih SMA Muhammadiyah 10 surabaya dalam bidang akademik maupun non akademik di tingkat lokal, nasional, bahkan internasional. Dalam bidang akademik, SMA Muhammadiyah 10 Surabaya merupakan salah satu yang terbaik dari sekolah-sekolah unggulan di Surabaya. Salah satu buktinya adalah Prestasi akademik juga ditunjukkan dengan beberapa kali menjadi pemenang dalam olimpiade-olimpiade nasional maupun internasional. Dalam bidang nonakademik, SMA Muhammadiyah 10 Surabaya terkenal berprestasi dalam bidang olahraga, di SMA X Surabaya terdapat 25 kegiatan ekstrakulikuler yakni bebrapa di antaranya basket, renang dan badminton, dayung, hockey. Berdasarkan hal tersebut tujuan penelitian ini yaitu mengembangkan budaya sekolah berprestasi: penanaman nilai dan etos berprestasi. 


\section{Metode}

Penelitian ini merupakan penelitian deskriptif kualitatif yang bertujuan untuk mengemukakan gejala-gejala secara lengkap serta hubungannya satu sama lain di dalam aspek-aspek yang diselidiki. Lokasi dalam penelitian ini adalah SMA Muhammadiyah 10 Surabaya . Penelitian ini menggunakan sumber data berupa data primer dan data sekunder. Data primer diperoleh dari subyek penelitian yakni guru dan peserta didik di SMA Muhammadiyah 10 Surabaya Intensitas yang rutin antara guru dan peserta dan kontak langsung dalam pembelajaran di dalam kelas maupun diluar kelas dapat menjelaskan tentang budaya sekolah berprestasi di SMA Muhammadiyah 10 Surabaya. Data primer yakni guru dan peserta didik tersebut diambil sampel (tidak seluruh guru dan peserta didik) dengan pertimbangan tertentu. Data sekunder didapatkan dari literatur-literatur relevan yang mendukung data penelitian yang diantaranya data sekolah, tata tertib sekolah, rekap data prestasi peserta didik dari tahun 2014-2019, data ekstrakurikuler majalah SMA MX Surabaya. Pengumpulan data dilakukan dengan teknik observasi, wawancara dan dokumentasi. Pelaksanaan observasi di lingkungan SMA Muhammadiyah 10 Surabaya dilakukan dengan prosedur ketat yang berlaku di sekolah tersebut. Observasi dilakukan tanpa mengganggu kegiatan pembelajaran. Observasi ditekankan pada fokus-fokus yang berkatan dengan rumusan masalah, yakni meliputi: lingkungan dan prasarana fisik sekolah, simbolsimbol yang berisi pesan-pesan positif berupa tulisan, gambar atau monument yang ada di lingkungan sekolah serta interaksi dan perilaku warga sekolah terutama para significant other dan peserta didik.

\section{Hasil dan Pembahasan Hasil Penelitian}

SMA Muhammadiyah 10 menciptakan generasi sekolah yang lebih siap menghadapi dunia perkuliahan dan dunia kerja, yang menyesuaikan dengan minat dan bakatnya. Sekolah ini lebih mengedepankan pendidikan real life skill. Konsep pendidikan lebih didahulukan materi praktek secara berkala, lalu secara perlahan didekatkan pada teori-teori ilmiah. Hal ini merupakan kebalikan dari konsep pendidikan pada umumnya. Siswa yang belajar di sekolah ini akan lebih banyak belajar mengenai materi-materi yang akan dihadapi pada bangku kuliah dan kehidupan nyata. Sedangkan materi pelajaran sekolah yang tidak berhubungan tidak harrus ditekuni dengan intensif. Pemilihan studi tidak hanya didasarkan pada pilihan jurusan standar seperti IPA (Ilmu Pengetahuan Alam) atau IPS (Ilmu Pengetahuan Sosial). Namun, lebih didasarkan pada minat melanjutkan studi selanjutnya (kuliah). Sehingga dari awal siswa akan memperoleh materi yang berkaitan dengan pilihanya tersebut.

Sekolah ini didesain untuk mengakomodasikan keinginan dan aspirasi siswa. Dimulai dari bakat dan minat mereka hingga pada pengembangan intelektualitasnya. Tata pelaksanaan sekolah dijalankan oleh siswa dan dipertanggungjawabkan. Guru adalah fasilitator dalam kegiatan bersekolah. Guru diharapkan menciptakan suasana pendidikan lebih semangat, fleksibel bagi siswa. Salah satu nilai karakter yang sangat menonjol dari sekolah Karangturi adalah Patriot. Patriot didasarkan pada nilai-nilai idealisme holistik dari Sekolah Karangturi dan nasionalisme. Pelaksanaan secara resmi dan menyeluruh untuk para guru, peserta didik, pengurus Yayasan dan karyawan dimulai tahun 2010, walaupun perintisannya sudah dikembangkan pada tahun-tahun sebelumnya. Nilai patriot menjadi penting dalam membentuk kepribadian peserta didik karena tidak hanya cukup belajar mengolah pikir tetapi harus mampu olah hati, dan olah rasa. Keseluruhan nilai-nilai patriot dijabarkan dalam empat nilai penting yaitu Mind, Heart, Body, Soul. Empat nilai penting di dalamnya masih terdapat 10 nilai dasar (The Ten Fundamental Values) yaitu: Mind yang meliputi 3 nilai yakni 
Creativity, Analytical Thinking, dan Global Mindset. Heart yang meliputi 4 nilai yakni Respect, Responsibility,

Sejarah pengembangan budaya berprestasi SMA Muhammadiyah 10 Surabaya dapat dianalisis menggunakan fungsi adaptasi dalam teori fungsional struktural. Perkembangan budaya berprestasi SMA Muhammadiyah 10 Surabaya yang bersifat dinamis menyesuaikan perkembangan masyarakat. Fungsi inilah sebagai penyesuaian dari sistem terhadap tuntutan dari lingkungan. Penyesuaian lingkungan itu ada dua jenis yaitu sosial dan fisik. Penyesuaian lingkungan sosial SMA Karangturi dalam perkembangannya terhadap tuntutan orientasi masyarakat dalam pendidikan yaitu yang berawal dari akademik dan nilai ujian dan beralih pola pikir yang mementingkan keseimbangan dalam kecerdasan akademik dan non akademik. Budaya sekolah di SMA Muhammadiyah 10 Surabaya meliputi empat poin yaitu: keseimbangan antara pembinaan akademik dan nonakademik, penanaman karakter yang bisa dilakukan pada pelajaran muatan lokal maupun masuk setiap pelajaran, budaya mencintai almamater, dan pentingnya nilai kerohanian atau spiritual dan nonakademik sangat penting untuk memberikan wadah untuk berbagai kecerdasan peserta didik di SMA Muhammadiyah 10 Surabaya sehingga menjadikannya prestasi yang membanggakan dan mendukung masa depan yang lebih baik. Peran sekolah yang begitu penting dalam memotivasi dari awal kepada peserta didik untuk berani percaya diri mengaktualisasikan segala potensi diri.

Keberhasilan di masa depan tidak hanya ditentukan oleh prestasi akademik. Peserta didik juga diarahkan untuk bisa mengembangkan non akademik. Penanaman karakter sangat penting untuk menguatkan jiwa berbudaya dan nasionalisme. SMA Muhammadiyah 10 Surabaya selain mengajarkan nilai-nilai karakter SMA Muhammadiyah 10 Surabaya dan semangat Patriot, juga mengajarkan bahasa dan budaya Jawa. Setiap hari kamis untuk seluruh warga sekolah memakai baju atasan batik dengan kebebasan motif coraknya dan setiap hari Jumat menggunakan seragam patriot. Pentingnya peserta didik mencintai almamater SMA Muhammadiyah 10 Surabaya mengandung makna agar peserta didik harus menikmati dan menyenangi pengalaman dalam proses pembelajaran sehingga menumbuhkan kecintaan yang mendalam terhadap SMA Muhammadiyah 10 Surabaya. Kecintaan terhadap almamater akan menjadikan SMA Karangturi selalu diperjuangkan bersama agar selalu berprestasi dan selalu memberikan masukan untuk kemajuan sekolah. Ikatan yang kuat antara para alumni dan SMA Muhammadiyah 10 Surabaya akan menjadikan jaringan informasi dan kerjasama yang mempermudah hubungan dengan dunia luar terutama untuk pengembangan sekolah maupun peserta didik. Menjunjung nilai kerokhanian atau spiritual juga merupakan budaya SMA Muhammadiyah 10 Surabaya. Sekolah mentransfer nilai spiritual kepada peserta didik dengan memaknai kegiatan sosial yaitu selalu memberi dan peduli sebenarnya tidak kehilangan apa yang telah diberikan tetapi akan menjadikan berkah yang lebih banyak sehingga menjadi kebutuhan rohani yang harus selalu dilakukan. Kepala Sekolah dan para guru sangat penting dalam pengembangan budaya

Keseimbangan antara pembina akademik dan non akademik sangat penting untuk memberikan wadah untuk berbagai ke-cerdasan peserta didik di SMA Muhammadiyah 10 Surabaya sehingga menjadikannya prestasi yang mem-banggakan dan akhirnya bisa mendukung masa depan yang lebih baik. Peran sekolah inilah yang begitu penting dalam memotivasi dari awal kepada peserta didik untuk berani percaya diri mengaktualisasikan segala po-tensi diri. Keberhasilan di masa depan bukan cuma ditentukan oleh prestasi akademik. Pe-serta didik juga diarahkan untuk bisa men-gembangkan secara seimbang kemampuan akademik dan non akademik. Penanaman karakter sangat penting untuk menguatkan jiwa berbudaya dan na-sionalisme. SMA Muhammadiyah 10 Surabaya selain mengajarkan nilai-nilai karakter sekolah dan semangat Patriot, juga mengajarkan bahasa dan budaya Jawa. Setiap hari kamis untuk seluruh warga sekolah memakai baju atasan batik dengan kebebasan motif corak-nya dan setiap hari Jumat menggunakan se-ragam Patriot. 
Pentingnya peserta didik mencintai almamater SMA Muhammadiyah 10 Surabaya mengandung makna agar peserta didik harus menikmati dan menyenangi pengalaman dalam pro-ses pembelajaran sehingga menumbuhkan kecintaan yang mendalam terhadap SMA Muhammadiyah 10 Surabaya. Kecintaan terhadap almamater akan menjadikan SMA Muhammadiyah 10 Surabaya selalu diperjuangkan bersama agar selalu berprestasi dan selalu memberikan masukan untuk kemajuan sekolah. Ikatan yang kuat antara para alumni dan SMA Muhammadiyah 10 Surabaya akan menjadikan jaringan informasi dan kerjasama yang mempermudah hubungan dengan dunia luar terutama untuk Muhammadiyah 10 Surabaya. Sekolah mentransfer nilai spiritual kepada peserta didik dengan memaknai kegiatan sosial yaitu selalu memberi dan peduli sebenarnya tidak kehilangan apa yang telah diberikan tetapi akan menjadikan berkah yang lebih banyak sehingga menjadi kebutuhan rohani yang harus selalu dilakukan.

Kepala Sekolah dan para guru sangat penting dalam pengembangan budaya kepala sekolah berprestasi. Kepala Sekolah menjadi pihak penting karena kepala sekolah adalah yang mengelola budaya sekolah dan yang memiliki kemampuan manajerial untuk pengelolaan kegiatan sekolah(Juniarti et al., 2019). Sementara itu guru merupakan pihak yang penting karena langsung berhadapan dengan peserta didik. Tugas pengembangan budaya sekolah berprestasi terutama perencanaan dan evalu-asi tidak bisa menjadi tanggung jawab pim-pinan sekolah SMA Muhammadiyah 10 Surabaya yang bersifat perintah atau TopBottom tetapi menjadi tugas bersama dan adakalanya bersifat Bottom Up. Guru juga bisa mengusulkan maupun ikut mengevaluasi kegiatan maupun program se-kolah yang berkaitan dengan budaya sekolah berprestasi di SMA Karangturi. Koordinasi dan kolaborasi bersama inilah menjadi faktor penting keserasian pandangan dan lang-kah untuk mencapai tujuan sekolah yang diharapkan(Hidayah, 2015; Permana \& Ulfatin, 2018). Penanaman nilai dan etos budaya se-kolah berprestasi SMA Muhammadiyah 10 Surabaya dilakukan melalui proses pembelajaran di kelas, evaluasi belajar, proses pembelajaran di luar kelas, ekstrakurikuler, pemberian penghar-gaan prestasi, penanaman melalui simbol-simbol motivasi dan afirmatif, membangun kecintaan terhadap almamater, membangun keteladanan guru, membagun kerjasama dengan orang tua peserta didik, serta pema-kaian seragam Patriot sebagai media pena-naman budaya berprestasi.Penanaman nilai dan etos budaya se-kolah berprestasi SMA Muhammadiyah 10 Surabaya memiliki faktor pendorong sekaligus penghambat. Salah satu faktor pendorong adalah sumber belajar yang berupa fasilitas yang tersedia di SMA Muhammadiyah 10 Surabaya yang bisa membantu pro-ses pembelajaran di SMA Muhammadiyah 10 Surabaya yang lebih mengutamakan keaktifan dan penga-laman peserta didik. Faktor pendorong lain adalah pembelajaran di SMA Muhammadiyah 10 Surabaya yang selalu mendukung untuk peserta didik untuk bisa mengembangkan materi pelaja-ran lebih luas lagi, menemukan manfaat dan bisa berprestasi di dalam dan di luar sekolah.

Pembelajaran yang menekankan proses bela-embelajaran yang menekankan proses bela-jar dan evaluasi belajar yang disiplin, ketat dan disertai budaya peserta didik maupun orangtuanya untuk meraih prestasi memacu atmosfir persaingan yang sangat kuat dan terlihat di lingkungan sekolah. Atmosfir per-saingan yang kuat di dalam kelas memberi-kan efek positif terhadap semangat belajar setiap peserta didik. Faktor pendorong yang lain adalah ketersediaan teknologi informasi dan kemampuan peserta didik SMA Muhammadiyah 10 Surabaya untuk dengan leluasa memanfaatkannya. Peserta didik di SMA Muhammadiyah 10 Surabaya yang mayoritas berasal dari keluarga ekonomi menengah ke atas, banyak yang memiliki perangkat kom-puter ataupun telepon genggam yang bisa terhubung dengan internet dan banyak juga yang mengikuti bimbingan belajar di luar sekolah. Hal ini sangat membantu dalam pro-ses belajar siswa sehingga dapat meningkat-kan hasil belajar. Faktor berikutnya yang mendorong penanaman budaya berprestasi adalah guru di SMA Muhammadiyah 10 
Surabaya yang mampu mengana-lisis kebutuhan peserta didik dari segi materi pelajaran, menggunakan metode pembelaja-ran yang lebih menyenangkan, memvisua-lisasikan dan mendekatkan pembelajaran dengan dunia nyata, mengembangkan metode pembelajaran yang bisa diterima dengan baik dan selalu memberikan motivasi.Faktor berikutnya adalah SMA Muhammadiyah 10 Surabaya memiliki program olimpiade dan persiapan kompetisi yang diadakan ketika ada kompetisi yang akan diikuti oleh seko-lah.

Ekstrakurikuler di SMA Muhammadiyah 10 Surabaya juga tidak hanya sebatas pengembangan bakat maupun hobi tetapi juga untuk mempersiapkan keikutsertaan dalam lomba maupun kompetisi sehingga tujuannya adalah prestasi. Hubungan yang baik antara orangtua peserta didik, sekolah dan yayasan Karang-turi dalam bentuk perhatian terhadap pres-tasi SMA Muhammadiyah 10 Surabaya juga menjadi faktor pendorong penanaman budaya berprestasi. Orangtua peserta didik selalu memantau prestasi anaknya, ketersediaan fasilitas bela-jar, dan proses pembelajaran yang berlang-sung di sekolah, dan memberikan masukan untuk kemajuan. Peran penting yayasan SMA Muhammadiyah 10 Surabaya dalam penanaman nilai berprestasi menjadi faktor pen-dorong Fungsi integration dalam pengembangan budaya sekolah berprestasi di SMA Muhammadiyah 10 Surabaya adalah dengan mengatur hubun-gan komponen-komponen pendidikan yang ada di dalamnya agar dapat berfungsi secara maksimal. Hubungan komunikasi yang baik diantara Yayasan Muhammadiyah, sekolah, peserta didik, keluarga, dan alumni akan mencipta-kan pemahaman yang sama mengenai nor-ma budaya sekolah sehingga dengan penuh kesadaran, kepercayaan dan kerelaan untuk mewujudkannya. Selain faktor pendorong yang telah disampaikan, terdapat pula beberapa faktor yang menghambat penanaman budaya ber-prestasi di SMA Muhammadiyah 10 Surabaya. Salah satunya adalah keterbatasan dalam memfasilitasi bakat nonakademik peserta didik di bidang olahraga tertentu, karena sempitnya lahan sekolah Karangturi untuk kegiatan olahraga. Selama ini SMAM X memang terkenal sangat berprestasi dalam olahraga hockey, namun untuk olahraga lainnya nampaknya sekolah ini kesulitan dalam pengembangan karena keterbatasan lahan. Hambatan lain yang dialami adalah sering terjadinya miskomunikasi orangtua peserta didik terutama kelas $\mathrm{X}$, yang tampak pada seringnya mereka memprotes sekolah mengenai banyaknya penugasan yang diberikan guru kepada peserta didik. Namun sekolah menganggap penugasan tersebut sangat penting untuk tetap dilakukan karena mem-beri keuntungan pada siswa saat menjalani proses pembelajaran maupun selepas SMA.

Bentuk proses dalam prestasi adalah kinerja sekolah yang memuat program sekolah, inovasi yang dikembangkan, kerjasama instansi maupun etos dalam upaya mendukung budaya berprestasi. Visi misi SMA Karangturi yang dilengkapi dengan falsafah pembelajaran dan karakter Patriot telah memberikan dasar yang kuat sekaligus arahan yang jelas untuk program-progam Bentuk proses dalam prestasi adalah kinerja sekolah yang memuat program sekolah, inovasi yang dikembangkan, kerja-sama instansi maupun etos dalam upaya mendukung budaya berprestasi. Visi misi SMA Muhammadiyah 10 Surabaya yang dilengkapi dengan falsafah pembelajaran dan karakter Patriot telah memberikan dasar yang kuat sekaligus arahan yang jelas untuk program-progam sekolah yang akan dikembangkan. Nilai-nilai semangat wirausaha berwawasan global telah dikembangkan dengan nilai-nilai dan etos kerja keras, disiplin, persaingan yang se-hat, kepemimpinan, dan kepedulian. Inovasi pembelajaran yang dikembangkan di dalam kelas, luar kelas (clinical dan tim olimpiade) maupun ekstrakurikuler menjadi strategi un-tuk selalu mengikuti perkembangan pendi-dikan.

Kerjasama SMA Muhammadiyah 10 Surabaya dengan beberapa sister school yang ada di luar nege-ri menjadi bukti pengembangan sekolah ke arah standar internasional. Profesionalisme yang tinggi dan hubungan antara guru, kepala sekolah dan yayasan yang dekat diwu-judkan dalam rapat bersama dalam hal per-kembangan inovasi pembelajaran, 
evaluasi prestasi sekolah, maupun bentuk keakraban (sharing, rekreasi bersama atau outbond).Dalam hal output, prestasi SMA Muhammadiyah 10 Surabaya berwujud dalam dua bentuk yaitu prestasi akademik dan prestasi non akade-mik. Prestasi SMA Muhammadiyah 10 Surabaya menunjukkan keseimbangan antara prestasi akademik dan prestasi non akademik. Prestasi yang diraih peserta didik SMA Muhammadiyah 10 Surabaya ini merupakan hasil budaya sekolah berprestasi yang ditanamkan mulai pertama kali masuk dan selama proses pembelajaran. Prestasi peserta didik SMA Muhammadiyah 10 Surabaya juga didukung oleh guru-guru dan pembina ekstrakurikuler yang banyak berkualitas dan ahli dalam bidang-nya serta keaktifan membina peserta didik untuk mengikuti kompetisi.

Temuan penelitian sebelumnya menyatakan sekolah tidak hanya memiliki kecerdasan pengetahuan tetapi juga cerdas secara emosional spiritual, berjiwa wirausaha, pekerja keras, tahan terhadap tekanan dan mempunyai banyak hubungan usaha (Pitaloka et al., 2021; Wisnu Budi Wijaya, 2019). Budaya berprestasi ini melekat sampai dunia kerja dan di kehidupan masyarakat menjadi pengusaha sekaligus pemimpin yang berkarakter dan berjiwa sosial(Permana \& Ulfatin, 2018; Silkyanti, 2019). Pengembangan budaya sekolah berprestasi memang tidak hanya dilihat dalam prosesnya, kelulusan maupun langsung terlihat hasilnya tetapi juga prestasi yang paling penting adalah karakter dalam jangka waktu yang lama. Output prestasi yang dianggap berharga adalah kesan yang baik oleh para alumni sehingga merasakan manfaatnya di masa depan.

\section{Simpulan}

Pengembangan budaya sekolah berprestasi di SMA Muhammadiyah 10 Surabaya mencakup empat poin yaitu: keseimbangan antara pembinaan aka-demik dan nonakademik, penanaman karak-ter yang bisa dilakukan pada pelajaran mua-tan lokal maupun masuk setiap pelajaran, budaya mencintai almamater dan penting-nya nilai kerohanian atau spiritual. Penanaman nilai dan etos berprestasi pada peserta didik di SMA Muhammadiyah 10 Surabaya melalui proses orientasi sekolah, proses pembelajaran di kelas (pembimbingan gaya belajar, kewirausahaan dan kepemimpinan), evaluasi belajar, proses pembelajaran di luar kelas (clinical, pagelaran sekolah, dan tour kampus), ekstrakurikuler, dan penghargaan prestasi. Implikasi penelitian ini diharapkan dapat memberikan dampak terhadap perkembangan budaya sekolah.

\section{Daftar Rujukan}

Asiyah. (2019). Pengaruh Rasa Percaya Diri Terhadap Motivasi Berprestasi Siswa pada Mata Pelajaran IPA. Jurnal Pendidikan Dan Kebudayaan, 9(3), 217-226. https://doi.org/10.24246/j.js.2019.v9.i3.p217-226.

Eva, M. (2016). Pengembangan Budaya Sekolah. Tarbawi, 2(02), 86-96.

Hendra Anggryawan, I. (2018). Pengaruh Fasilitas Belajar dan Motivasi Belajar Terhadap Hasil Belajar Siswa Pada Mata Pelajaran Ekonomi. Jurnal Pendidikan Ekonomi (JUPE), 2(1), 19-28. https://doi.org/10.26740/jupe.v7n3.p71-75.

Hidayah, N. (2015). Penanaman Nilai-nilai Karakter Dalam Pembelajaran Bahasa Indonesia di Sekolah Dasar. Jurnal Pendidikan Dan Pembelajaran Dasar, 2(2). https://doi.org/10.24042/terampil.v2i2.1291.

Juniarti, E., Ahyani, N., \& Ardiansyah, A. (2019). Pengaruh Kepemimpinan Kepala Sekolah Dan Efikasi Diri Guru Terhadap Kinerja Guru. Reslaj : Religion Education Social Laa Roiba Journal, 1(3), 193-199. https://doi.org/10.47467/reslaj.v1i2.108.

Kurniawan, M. W. (2021). Penguatan Karakter Religius Berbasis Budaya Sekolah di SD Muhammadiyah 4 Batu. Elementary School, 8(2), 295-302. 
https://doi.org/10.31316/esjurnal.v8i2.1393.

Permana, B. I., \& Ulfatin, N. (2018). Budaya Sekolah Berwawasan Lingkungan pada Sekolah Adiwiyata Mandiri. Jurnal Kajian Teori Dan Praktik Pembelajaran, 2(1). https://doi.org/10.17977/um027v3i12018p011.

Pitaloka, D. L., Dimyati, D., \& Purwanta, E. (2021). Peran Guru dalam Menanamkan Nilai Toleransi pada Anak Usia Dini di Indonesia. Jurnal Obsesi : Jurnal Pendidikan Anak Usia Dini, 5(2), 1696-1705. https://doi.org/10.31004/obsesi.v5i2.972.

Polapa, I. (2018). Hubungan antara Budaya OOrganisasi dan Persepsi Guru tentang Kepemimpinan Kepala Sekolah dengan Motivasi Berprestasi Guru. 2(1), 30-39.

Pratama, R. S., Hidayah, T., \& Haryono, S. (2019). Konservasi Budaya Berprestasi Melalui Olahraga Petanque Pada Siswa Sekolah Dasar Se Kabupaten Purbalingga. Journal of Sport Coaching and Physical Education, 3(1), 30-35. https://doi.org/10.15294/jscpe.v3i1.31910.

Prayogi, D. S., Utaya, S., \& Sumarmi, S. (2019). Internalisasi Kearifan Lokal Dalam Pembelajaran melalui Pengembangan Multimedia Interaktif Muatan Pembelajaran IPS. Jurnal Pendidikan: Teori, Penelitian, Dan Pengembangan, 4(11), 1457-1463.

Rachmawati, W., Benty, D. D. N., \& Sumarsono, R. B. (2018). Budaya Sekolah Berbasis Ketarunaan Dalam Pembentukan Karakter Peserta Didik. Jurnal Administrasi Dan Manajemen Pendidikan, 1, 410-418. https://doi.org/10.17977/um027v1i42018p410.

Rahman, E. S., Sari, T. T., \& Meita, N. M. (2019). Pengembangan Buku Saku Tematik Sd Berbasis Kearifan Budaya Lokal. Jurnal Pendidikan Dasar, 3(2), 70-78. https://doi.org/10.24929/alpen.v3i2.28.

Ramdan, A. Y., \& Fauziah, P. Y. (2019). Peran orang tua dan guru dalam mengembangkan nilai-nilai karakter anak usia sekolah dasar. Jurnal Pendidikan Dasar Dan Pembelajaran, 9(2), 100. https://doi.org/10.25273/pe.v9i2.4501.

Rozaini, N. (2017). Pengaruh Motivasi Belajar dan Kepercyaan Diri Siswa terhadap Prestasi Belajar. Jurnal Niagawan, 6(2). https://doi.org/10.24114/niaga.v6i2.8335.

Silkyanti, F. (2019). Analisis Peran Budaya Sekolah yang Religius dalam Pembentukan Karakter Siswa. Indonesian Values and Character Educational Journal, 2(1), 36-42. https://doi.org/10.23887/ivcej.v2i1.17941.

Wisnu Budi Wijaya, I. K. (2019). Menanamkan Konsep Catur Paramita Pada Anak Usia Dini Di Lingkungan Keluarga Dan Sekolah. Pratama Widya: Jurnal Pendidikan Anak Usia Dini, 3(2), 41-46. https://doi.org/10.25078/pw.v3i2.737. 